\title{
Effect of egg sizes on egg qualities, hatchability and initial weight of the hatched-chicks
}

\author{
Ayeni, A.O.*; Agbede, J.O.; Igbasan, F.A.; Onibi, G.E. and Adegbenro, M
}

Department of Animal Production \& Health, The Federal University of Technology, Akure, Nigeria, (www.futa.edu.ng)

*Corresponding author: aoayeni@futa.edu.ng

\begin{abstract}
The study evaluates the relationship of egg weights with other egg qualities, hatchability and hatchling weights. One thousand eight hundred eggs from marshal broiler chicken were categorized into small $(50-59 \mathrm{~g})$, medium $(60-69 \mathrm{~g})$ and large $(\geq 70 \mathrm{~g})$ of 600 eggs per group in a completely randomized design. Hundred eggs from each group were subjected to quality analysis and the remaining incubated for hatchlings production. The egg length of of large group was the highest $(4.71 \mathrm{~cm})$ and lowest in small $(4.22 \mathrm{~cm})$. The relationship revealed $32.86 \%$ yolk in small size, while 33.71 and $30.99 \%$ was observed for medium and large respectively. Also, albumen ranged from $50.85 \%$ in small to $55.38 \%$ in large. Hatchability result revealed $74.50 \%$ for small egg and reduced as sizes increased. Hatchling weight was highest in large (49.19 g) and lowest in small $(38.79 \mathrm{~g})$. The regression equations showed that albumen weight and egg size were best predictors of chick's weight through their $R^{2}$ values ( 0.68 and 0.57 respectively) compared to yolk weight with $R^{2}$ of 0.28. It was therefore be inferred that breeder eggs size could affect egg quality parameters and chick's weight.
\end{abstract}

Keyword-Egg weights, hatchability, Egg quality, chick weight.

\section{INTRODUCTION}

The distributions of domestic chicken are on the increase in rural and urban areas of the world and in particular Africa and Asia where they contribute significantly to economic developments of the households. They are nutritionally, economically, and culturally very important to livelihoods of rural households (King'ori et al., 2003; Mtileni et al., 2010). However, productivity of these chickens is generally low and mortality is high, which suggest that appropriate genetic, nutritional and management interventions are needed to realize their optimal production potential (Okitoi et al., 2006; Mbajiorgu et al., 2011). Studies on improving productivity of broiler chickens through genetic and nutritional strategies have been well documented (Mbajiorgu et al., 2011; Adesola et al., 2012). Aside, other relevant factors that could affect the economic development of broiler chicken are needed to be examined. Such factors include the quality of day-old chick and the egg that produced the hatched chick.

The influence of egg weight on hatchability, chick weight and subsequent growth rate and mortality of these chicks is of practical interest to chicken farmers. However, there are ample evidences that egg weight affects subsequent productivity of laying hens and broiler chickens (Alders and Spradbrow, 2001; Swatson et al., 2001; King'ori et al., 2003; Rashid et al., 2005). Alabi et al. (2012a) reported that hatchability and chick weight were higher in larger broiler chicken eggs but the influence of egg weight on productivity of the progenies was not determined. Alabi et al. (2012b) then reported that hatchability and post-hatch performance of Potchefstroom Koekoek chickens were higher in larger eggs than in smaller ones. Williams (1994) studied the relationship between egg size and offspring quality in birds and reported that egg size typically affects hatchling mass more strongly than it affects hatching size in birds because the main effect of egg size lies in the mass of the residual yolk sac that the chick retains at hatching. Also, egg weight and chick weight at hatching have been shown to be positively related (Khurshid et al., 2003). The embryo size before and at hatching can be altered by the weight of the egg and the incubation environment (Wilson, 1991). It could therefore be suggested that the potential of the broiler chicken depends, in part, on egg quality, an important parameter for embryogenesis as well as for day-old chick quality and growth. In hatchery, the quality of a day-old chick is usually based on qualitative aspects, such as abnormalities and contamination. This study thus examines the effects of egg sizes on other egg quality parameters, hatchability and the weight of the resulting hatched chicks.

\section{MATERIALS AND METHODS}

\section{Experimental site}

The egg quality parameters evaluation was carried out at Animal Production and Health laboratory of The Federal University of Technology, Akure, Nigeria. While the incubation and hatching of fertile eggs were done at a reputable hatchery in Ilara-Mokin, Nigeria. These are located 
in the rainforest zone, South West, Nigeria with about 1200$1500 \mathrm{~mm}$ of average rainfall per annum (Nigerian Meteorological Agency, 2014).

\section{Hatchable Eggs Sourcing}

One thousand eight hundred marshal broiler chicken eggs were sourced from Oluade breeder farm in Ilara-Mokin, Ondo State, Nigeria. The eggs were cleaned and grouped based on sizes into small $(50-59 \mathrm{~g})$, medium $(60-69 \mathrm{~g})$ and large $(\geq 70 \mathrm{~g})$. After grouping, the eggs were stored in the cold room to arrest embryonic development prior to incubation.

Egg Quality Parameters Assessment and Hatching of Eggs

A total number of three hundred (300) eggs selected from the three sizes (i.e. small, medium and large) with 100 eggs per group were subjected to quality analysis in the laboratory. The eggs parameters that were assessed included; shape index, shell thickness, albumen index, yolk index, yolk weight, albumen weight, yolk height, albumen height and Haugh unit. Some of these parameters were calculated using the following formulae and methods summarized by Yoruk et al. (2004).

Shape index $(\%)=($ egg width, $\mathrm{cm} /$ egg length, $\mathrm{cm}) \times 100$;

Shell thickness $\left(\mathrm{mm} \times 10^{-2}\right)$ was determined in 3 different parts with a micrometer screw gauge;

Albumen index $(\%)=$ (albumen height, $\mathrm{mm} /$ average of albumen length, $\mathrm{mm}$ and albumen width, $\mathrm{mm}) \times 100$;

Yolk index $(\%)=($ yolk height, $\mathrm{mm} /$ yolk diameter, $\mathrm{mm}) \times$ 100 ;

Haugh unit $=100 \times \log \left(\mathrm{AH}+7.57-1.7 \times \mathrm{EW}^{0.37}\right)$, where $\mathrm{AH}=$ albumen height $(\mathrm{mm})$ and $\mathrm{EW}=$ egg weight $(\mathrm{g})$. Before the egg quality parameters were determined, the eggs were stored for 24 hours at a room temperature.

The hatching of eggs was done based on the procedure provided by the hatchery.

Determination of hatchability of egg and initial weight of hatched chicks

One thousand five hundred eggs of 500 eggs per group were set in the setter according to their groups (small, medium and large). The eggs spent a total number of 21 days in the incubator, after which the chicks were brought out. Counting was done based on the ranges set in the incubator. Percentage hatchability was also determined using the formula;

$\%$ hatchability $=\frac{\text { total number of hatched chicks }}{\text { total number of fertile eggs incubated }} \times 100$

Thereafter, the initial weight of each chick was determined using a digital sensitive scale (Wiggen Hauser, WH 200-4, Germany).

\section{Experimental Design and Data Analysis}

The design of the experiment was a Completely Randomized Design (CRD) with one thousand eight hundred eggs of 600 eggs per group, out of which 100 eggs per group were used for egg quality assessment and the remaining for hatching. All data collected were analyzed by subjecting them to One Way Analysis of Variance using SPSS version 16 package. Where significant differences were found, Duncan multiple Range Test of the same package was used to separate the means. The regression equations were fitted using the mean values of the weight range.

\section{RESULTS}

\section{Quality characteristics of different egg sizes}

The result of the quality characteristics of the different egg sizes of broiler chicken presented in Table 1 showed that there were relationships between the egg sizes and some egg qualities as significant $(\mathrm{P}<0.05)$ differences were observed in the egg length, egg width, yolk weight, yolk length, yolk height, albumen weight and albumen length. A significant ( $P$ $<0.05)$ difference noticed in the egg length as a result of the egg sizes revealed that egg categorized as large $(\geq 70)$ had the highest egg length $(4.71 \mathrm{~cm})$ followed by those categorized as medium $(4.49 \mathrm{~cm})$ and lowest in those categorized as small $(4.22 \mathrm{~cm})$. The same trend was also noticed in the egg width, albumen weight and albumen length (large > medium > small). The yolk weight and length recorded for the large group though not statistically $(\mathrm{P}>$ 0.05) different from those in medium group were higher than those recorded for the small group. However, the yolk height of eggs categorized as medium was significantly $(\mathrm{P}<0.05)$ higher than those categorized as small. The shell thickness shows no significant variation with respect to egg sizes. The albumen index decreased as the weight of the eggs increased. The same trend was noticed in the haught unit of the eggs though not significantly $(P>0.05)$ affected.

\section{Correlation of egg sizes with egg yolk and albumen}

Correlation of egg sizes with egg yolk and albumen revealed that the coefficients for egg size with egg yolk and albumen were positive in all the sizes and were highly significant (Table 2). The small categories had significantly $(\mathrm{P}<0.01)$ higher egg/yolk weight correlation (0.88) than other groups and lowered as the egg sizes increased. However, the egg/albumen weight correlation was highest in the medium group (0.85) followed by the small group (0.79) and the large group (0.62).

\section{Effect of egg sizes on hatchability and the Initial weight of} day-old chicks

The result of the egg sizes in relation to hatchability and dayold chick weight revealed that there was a significant (P < 0.05 ) difference in the hatchability of the egg due to sizes (Table 3). The eggs categorized as small had the highest percentage of hatchability ( $74.50 \%)$, followed by the medium $(72.50 \%)$, and the lowest in the eggs categorized as large 
(69.49\%). However, the initial weight of the hatched chicks was highest in large size eggs with mean value of $49.19 \mathrm{~g}$, followed by the medium $(42.72 \mathrm{~g})$ and the lowest value was recorded in the small size egg $(38.79 \mathrm{~g})$.

\section{Effects of egg sizes on yolk, albumen and chick weight}

The relationships between egg size and yolk weight reveals that $32.86 \%$ of the small size eggs were made up the yolk, while 33.71 and $30.99 \%$ made up the medium and large groups respectively (Table 4). The contribution of albumen to the entire egg ranged from $50.85 \%$ in small size to $55.38 \%$ in the large group. In addition, the ratio of egg to chick indicated that about $70 \%$ of egg in the small group translates to chicks, while it was 64 and $68 \%$ for medium and large groups respectively. Also, the small sized group had the lowest egg to chick weight loss (16.50 g), while the large had the highest but this was not significantly $(\mathrm{P}>0.05)$ different from those in the medium. However, the \% reduction in weight from egg to chick reveals that medium sized eggs had the highest reduction with $35.99 \%$ followed by the large (31.28\%) with the small group having the lowest (29.79\%) (Table 4).

Regression equations derived from parameters of the relationship between the day-old chick weight and other egg qualities

Table 5 shows the regression equations, estimates and coefficients of determination of day-old chick weight measurements in relation to egg sizes, albumen and yolk weights. The relationship between the day-old chick weight and egg sizes as indicated by the coefficient of determination $\left(\mathrm{R}^{2}\right)$ had a positive value for regression coefficient (0.57). Also, the relationship between the day-old chick weight and albumen weight shows a positive coefficient of determination $(0.68)$ which is more than that of the yolk weight $(0.29)$.

\section{DISCUSSION}

The physical characteristics of the egg have been shown to play an important role in the embryonic development process and a successful hatching (Narushin and Romanov, 2002). In addition, the most influential physical egg characteristics include egg weight, shell thickness and porosity and shape index. The significant differences observed in the egg weight, egg length, egg width, yolk weight, yolk length, yolk height, albumen weight and albumen length further confirmed that these parameters are function of egg size. The coefficient of correlation of egg sizes with yolk and albumen weights in this study were generally high and positive, suggesting that both the yolk and albumen weight highly significantly contributed to the weight of the egg. The relationship between egg size and yolk weight revealed that $32.86 \%$ of the small sized egg was contributed by the yolk, while it was 33.71 and $30.99 \%$ for medium and large groups respectively. However, the contribution of albumen to the entire egg ranged from $50.85 \%$ in small size to $55.38 \%$ in the large group. This was contrary to the report of North and Bell (1990) that as egg size increases, yolk size increases more than the quantity of albumen. The present study therefore suggests that the albumen weight contributed more to egg weight than yolk weight having contributed about $53 \%$ to the entire egg weight.

The reproductive efficiency of broiler breeders decreases with age, which is related to the internal egg composition or ratio, too large egg weight, poor shell quality leading to increased early and late embryo mortality (North and Bell, 1990; Benette, 1992; Vieira and Moran, 1998; Leeson and Summers, 2000; Tona et al., 2004; Joseph and Moran, 2005a; Elibol and Brake, 2008) and albumen quality deterioration (Lapao et al., 1999; Tona et al., 2004) and increase in yolk cholesterol content (Dikmen and Sahan, 2007).

The yolk index though not according to a particular pattern (ranged: 0.35- 0.37) in this study was lower than 0.50 reported for Fulani-ecotype chicken by Fayeye et al. (2005) but the haugh unit (ranged: 75-77) was similar and sometime higher than $75.50 \%$ for Fulani-ecotype chicken by the same authors. These further confirmed that the range of eggs used in this study could be desirable since these two indices were regarded as the best indicators of internal egg quality (Isikwenu et al., 1999), and the higher the yolk index (Ayorinde 1987) and haugh unit the more desirable the egg quality. With reference to Ihekoronye and Ngoddy (1985) high quality egg generally have haugh unit of 70 and above. The result of this study also showed that weight of broiler chicken eggs had a significant effect on egg hatchability. Heavier eggs $(\geq 70 \mathrm{~g})$ had lower hatchability percentage $(69.49 \%)$ while the small group $(50-59 \mathrm{~g})$ had the highest (74.50\%). This is in agreement with the findings of Constantini and Panella (2001) who reported that eggs with heavier weight have lower hatchability. This could be due to difference in egg weight, egg components like the yolk and albumen percentage, yolk: albumen ratio and incubation time (Suarez et al., 1997; Joseph and Moran, 2005b). Yannakopoulos and Tserveni-Gousi (1999) also reported similar results for Japanese chicken. In the result of the latter, it was noted that eggs with heavier weight which were incubated have the lowest hatchability. However, Gonzalez et al. (1999) and Abiola et al. (2008) found contrary results. These authors found that broiler chicken eggs of medium weight (60-69 g) are more suitable for setting in order to obtain higher hatchability. Farooq et al. (2001) and Narkhede et al. (1981) found negative correlations between egg weight and hatchability in crossbred chickens as heavier eggs 
resulted in lower hatchability. These observations were also similar to those made by Deeming (1995) and De Witt and Schwalbach (2004), who found that hatchability of eggs of ostrich, New Hampshire and Rhode Island Red breeds decreased with increasing egg weight. On the contrary, large sized eggs of indigenous Venda chickens had been reported to have higher hatchability than medium and small sized eggs (Mbajiorgu et al., 2011).

The effect of egg weight on chick weight was significantly higher in heavier egg sized group with the medium group having higher chick weights of about $10.13 \%$ over the small group, while chick's weight from the large group was 15.15 and $26.81 \%$ over the medium and small groups respectively. This was positively and highly correlated with equation $\mathrm{Y}=$ $12.48+0.49 X_{1}, R^{2}=0.57$. This finding could be due to the fact that heavier eggs contain more nutrients than small eggs (Williams, 1994), which resulted in developing embryos from heavier eggs having more nutrients for their growth requirements. This finding is in agreement with the finding of Vieira et al (2005) who found higher chick weight in large size egg in comparison with small ones in 40 weeks old Ross-38 breeders. However, contrary results were found by Asuquo and Okon (1993) which indicated that egg size within the intermediate weight range of 45 to $56 \mathrm{~g}$ hatched heavier chicks than small or large eggs. Ng'ambi et al (2013) also found similar observation that egg weight was positively correlated with chick hatch-weight in venda chicken. The increase in chick's weight with increasing egg weight was adjudged to the fact that heavier egg contains more nutrient than small egg (Willams, 1994). However, chicks from larger eggs have been shown to have more yolk attachment at hatching (Hassan et al., 2005; Wolanski et al., 2006). Hence heavier chicks tend to present higher body development and smaller yolk sacs due to higher development during incubation, or less developed bodies and larger yolk sacs, allowing them to survive longer before exogenous feed is provided (Skewes et al., 1988). It was therefore concluded that chicks tend to depend on this yolk during the first few hours after hatching (Deeming, 1995). The yolk attachment is utilized by the chicks after hatching and the potential performance of day-old chicks may depend on the quality and quantity of this yolk. In the current study, the ratio of egg to chick indicated that about $70 \%$ of egg in the small group translates to chicks, while it was 64 and $68 \%$ for medium and large groups respectively. From the result, it was observed that the small sized group had the lowest egg to chick weight loss $(16.50 \mathrm{~g})$, while the large had the highest but similar to those in the medium. These results were consistent with those reported by Guill and Washburn (1973) for broiler chickens. Chick/egg weight ratio in the current study was independent of maternal age, as found by Morris et al. (1968), who observed that this ratio remained virtually constant over the full range of egg weight.

The regression equations estimates and coefficients of determination $\left(\mathrm{R}^{2}\right)$ of day-old chick weight measurements in relation to egg sizes $\left(\mathrm{Y}=12.48+0.49 \mathrm{X}_{1}\right)$, albumen weight $\left(\mathrm{Y}=17.95+0.77 \mathrm{X}_{3}\right)$ and yolk weight $\left(\mathrm{Y}=20.62+1.12 \mathrm{X}_{2}\right)$ showed that albumen weight and egg sizes could be used for predicting chick weight in Arbor acre breed of broiler with $\mathrm{R}^{2}$ of 0.68 and 0.57 respectively, while the yolk weight may not give a stable prediction for the day-old chick weight having $\mathrm{R}^{2}$ of 0.28 . By implication also, the egg size and albumen weight account for about 57 and $68 \%$ respectively, of the variation in chick weight while it was just $28 \%$ of yolk. Thus, for every unit increase in egg weight and albumen weight, there would be a corresponding increase of 0.49 and 0.77 respectively in chick weight, while other factors aside egg weight and albumen weight require 12.48 and 17.95 , respectively.

\section{CONCLUSION}

It could therefore be concluded that there were strong relationships between the egg sizes and some egg qualities in Arbor acre broiler chicken. Egg categorized as large $(\geq 70)$ had the highest egg length, egg width, yolk weight, yolk length, yolk height, albumen weight and albumen length followed by those in medium size. Egg categorized as small had higher egg/yolk weight correlation than other groups and lowered as the egg sizes increased. Also, eggs categorized as small had the highest percentage of hatchability and decreased as the egg sizes increased. However, the initial weight of the hatched chicks was highest in large eggs.

\section{ACKNOWLEDGEMENT}

I would like to appreciate Oluade Farm, Ilara-Mokin, Ondo State, Nigeria for allowing us to use her facilities.

\section{REFERENCES}

[1] Abiola, S.S., Meshioye, O.O., Oyerinde, B.O. \& Bamgbose, M.A. (2008). Effect of egg size on hatchability of broiler chicks. Arch. Zootech., 57: 83-86

[2] Adesola, A.A., Ng'ambi, J.W. \& Norris, D. (2012). Effect of ascorbic acid supplementation level to the diets of indigenous Venda hens on egg production, hatchability and subsequent productivity of chicks. Africa Journal Biotechnology. 11: 12606-12611.

[3] Alabi, O.J., Ng'ambi, J.W. \& Norris, D. (2012a). Effect of egg weight on physical egg parameters and hatchability of indigenous Venda chickens. Asian Journal of Animal. Veterinary Advances. 7: 166172 
[4] Alabi, O.J., Ng'ambi, J.W., Norris, D. \& Mabelebele, M. (2012b). Effect of egg weight on hatchability and subsequent performance of Potchefstroom Koekoek. Asian Journal of Animal Veterinary Advances. 7, 718725.

[5] Alders, R.G. \& Spradbrow, P.B. (2001). Controlling Newcastle disease in village chickens: A Field Manual. ACIAR Monograph. 82: 112-116.

[6] Birkhead, T.R. \& Nettleship, D.N. (2001). The adaptative significance of egg size and laying date in Thick-billed Murres (Uria lomvia L.). Neshein, M.C (1976): Poultry production.

[7] Constantini, F. \& Panella, F. (2001). Correlations between egg weight chick weight and broilers performance. Animal Breeding Abstract 51: 35-40.

[8] Das, S.K. (1994). Poultry Production, First edn., CBS Publishers and Distributors, Shahdara Delhi, India, pp. 41.

[9] Deeming, D.C. (1995). Factors affecting hatchability during commercial incubation of Ostrich (Struthio camelus) eggs. British Poultry Science 36(1): 51-65

[10] Farooq, M., Durrani, F.R., Aleem, M., Chand, N. \& Muquarrab, A.K. (2001). Egg traits and hatching performance of Desi, Fayumi and Rhode Island Red chicken. Pakistan Journal of Biological Science 4: 909911

[11] Gonzalez, A., Satterlee, D.G., Moharer, F. \& Cadd, G.G. (1999). Factors affecting ostrich egg hatchability. Poultry Science 78: 1257-1262.

[12] Hassan, S.M., Siam, A.A., Mady, M.E. \& Cartwright, A.L. (2005). Egg storage period and weight effects on hatchability of ostrich (Struthio camelus) eggs. Poultry Science 84: 1908-1912

[13] Khurshid, A., Farooq, M., Durrani, F.R., Sarbiland, K.and Chand, N. 2003. Predicting egg weight, shell weight, shell thickness and hatching chick weight of Japanese quails using various egg traits as regressors. International Journal of Poulry Science. 2(2): 164-167.

[14] King'ori, A.M., Tuitoek, J.K., Muiruri, H.K. \& Wachira, A.M. (2003). Protein requirements of growing indigenous chickens during the 14-21 weeks growing period. South Africa Journal Animal Science 33: 78-81.

[15] Mbajiorgu, C.A., Ng'ambi, J.W.- \& Norris, D. (2011). Effect of varying dietary energy to protein ratio level on growth and productivity of indigenous Venda chickens. Asian Journal of Animal Veterinary Advances. 6: 344352.

[16] Mtileni, B.J., Muchadeyi, F.C., Maiwashe, A., Phitsane, P.M., Halimani, T.E., Chimonyo, M. \& Dzama, K. (2010). Characterisation of production systems for indigenous chicken genetic resources in South Africa. Application Animal.Husbandry of Rural Development. 2, 18-22.

[17] Narkhede, J. S., Thatte, V.R. Singh, S.N., Kinhikar, V. N. \& Deshmukh, S. N. (1981). Study on fertility, hatchability and relationship between egg weight and hatch weight. Poultry Science 16:421-424

[18] Narushin, V.G. \& Romanov, M.N. (2002). Egg physical characteristics and hatchability. World's Poultry Science 58: 297-303.

[19] Kargbo K., Kanu S, P.(2017).Egg quality characteristics of pullet chickens fed Neem (AzdirachtaIndica) leaf meal (NLM) managed under two housing systems. International Journal of Environment Agriculture and Biotechnology(ISSN: 2456-1878).2(4), 20002004.10.22161/ijeab/2.4.57

[20] Nigerian Meteorological Agency (2014). Archives.; $P p 1: 1-2$. nimet.gov.ng/akure-weather/12.5

[21] Okitoi, L.O.-, Udo, H.M.J., Mukisira EA de Jong, R. \& Kwakkel, R.P. (2006). Evaluation of low - Input interventions for improved productivity of indigenous chickens in Western Kenya. Agriculture in Tropic and Sub-tropic 39, 178-181.

[22] Pearson, R.A.- \& Herron, K.M. (2003). Effects of energy and protein allowances during lay on the reproductive performance of broiler breeder hens. British Poultry Science 22: 227239.

[23] Rashid, M.M., Islam, M.N., Roy, B.C., Jakobsen, K. \& Lauridsen, C. (2005). Nutrient concentrations of crop and gizzard contents of indigenous scavenging chickens under rural conditions of Bangladesh. Livestock Research of Rural Development. 17, 122-132.

[24] Swatson, H.K., Nsahlai, I.V. \& Bycbwa, B. (2001). The status of smallholder poultry production in the Alfred district of KwaZulu-Natal, South Africa: Priorities for intervention. Department of Animal and Poultry Science, University of Natal, Pietermaritzburg, South Africa. 63-72

[25] Tona, K., Bamelis, F., De Ketelaere, B., Bruggeman, V. \& Decuypere, E. (2002). Effect of inducing molting on albumen quality, hatchability and chick body weight from broiler breeders. Poultry Science 81:327-332.

[26] Vieira, S.L. \& Moran, JR. E.T. (1998). Effects of extremes in egg weight from broiler breeder Sflocks of diverse strain crosses on live performance, carcass quality, and further processing yields. Poultry Science 75: 69-73

[27] Williams, T.D. (1994). Intraspecific variation in egg size and egg composition in birds: Effects on offspring fitness. Biology Revision 68: 35-39. 
[28] Wilson, H.R. (1991). Interrelationships of Egg Size, Chick Size and Posthatching Growth and Hatchability. World's Poultry Science Journal 47: 5-20.

[29] Wolanski, N.J., Renema, R.A., Robinson, F.E., Carney, V.L. \& Fancher, B.I. (2006). Relationship between chick conformation and quality measures with early growth traits in males of eight selected pure or commercial broiler breeder strains. Poultry Science 85:1490-1497.
[30] Yannakopoulos, A.L. and Tserveni-Gousi, A.S. 1999. Relationship of parent's age, hatching egg weight, and shell quality to day-old chick weights as influenced by oviposition time. Poultry Science 66: 829-833.

[31] Yoruk, M.A., Gul, M., Hayirli, A. \& Macit, M. (2004). The effects of supplementation of humate and probiotic on egg production and quality parameters during the late laying period in hens. Poultry Science, 83: 84-8

Table.1: Quality characteristics of different egg sizes

\begin{tabular}{lccccc}
\hline PARAMETERS & $\begin{array}{c}\text { SMALL } \\
\mathbf{5 0 - 5 9} \mathbf{~ g}\end{array}$ & $\begin{array}{c}\text { MEDIUM } \\
\mathbf{6 0 - 6 9} \mathbf{~ g}\end{array}$ & $\begin{array}{c}\text { LARGE } \\
\mathbf{2 7 0} \mathbf{g}\end{array}$ & $\mathbf{\pm S E M}$ & P-value \\
\hline Egg weight $(\mathrm{g})$ & $54.99^{\mathrm{c}}$ & $65.82^{\mathrm{b}}$ & $72.19^{\mathrm{a}}$ & 0.99 & 0.001 \\
Egg length (cm) & $4.22^{\mathrm{c}}$ & $4.49^{\mathrm{b}}$ & $4.71^{\mathrm{a}}$ & 0.04 & 0.015 \\
Egg width (cm) & $2.65^{\mathrm{c}}$ & $2.99^{\mathrm{b}}$ & $3.12^{\mathrm{a}}$ & 0.03 & 0.01 \\
Yolk weight (g) & $18.11^{\mathrm{b}}$ & $22.17^{\mathrm{a}}$ & $22.34^{\mathrm{a}}$ & 0.31 & 0.01 \\
Yolk length (cm) & $4.51^{\mathrm{b}}$ & $4.76^{\mathrm{a}}$ & $4.77^{\mathrm{a}}$ & 0.03 & 0.02 \\
Yolk height (mm) & $16.10^{\mathrm{b}}$ & $17.89^{\mathrm{a}}$ & $16.68^{\mathrm{b}}$ & 0.25 & 0.02 \\
Yolk index (\%) & 36.42 & 37.65 & 35.10 & 0.62 & 0.18 \\
Albumen weight (g) & $27.94^{\mathrm{c}}$ & $33.69^{\mathrm{b}}$ & $40.00^{\mathrm{a}}$ & 0.70 & 0.03 \\
Albumen length (cm) & $9.07^{\mathrm{c}}$ & $9.76^{\mathrm{b}}$ & $10.52^{\mathrm{a}}$ & 0.12 & 0.02 \\
Albumen height (mm) & 6.10 & 6.47 & 6.16 & 0.18 & 0.26 \\
Albumen index (\%) & $6.85^{\mathrm{a}}$ & $6.66^{\mathrm{a}}$ & $5.89^{\mathrm{b}}$ & 0.22 & 0.014 \\
Shell thickness (mm) & 0.33 & 0.33 & 0.35 & 0.05 & 0.28 \\
Shape index (\%) & 63.42 & 66.60 & 66.62 & 0.79 & 0.16 \\
Haugh unit (\%) & 77.48 & 76.46 & 75.28 & 1.38 & 0.31 \\
\hline
\end{tabular}

a.b.c, : Means with different superscripts within a column are significantly $\operatorname{different}(\mathrm{P}<0.05)$

Table.2: Correlation of egg sizes with egg yolk and egg albumen weights

\begin{tabular}{lll}
\hline Egg Sizes & Correlation Coefficient & \\
\cline { 2 - 3 } & Yolk & Albumen \\
\hline Small & $0.88^{* *}$ & $0.79^{* *}$ \\
Medium & $0.79^{* *}$ & $0.85^{* *}$ \\
Large & $0.69^{* *}$ & $0.62^{* *}$ \\
\hline
\end{tabular}

Table.3: Effects of egg sizes on hatchability and the initial weight of hatched chicks

\begin{tabular}{llll}
\hline TREATMENT & HATCHABILITY $(\%)$ & $\begin{array}{l}\text { WEIGHT OF DAY OLD } \\
\text { CHICKS (g) }\end{array}$ & \\
\hline SMALL & $74.50^{\mathrm{a}}$ & $38.79^{\mathrm{c}}$ & \\
MEDIUM & $72.50^{\mathrm{b}}$ & $42.72^{\mathrm{b}}$ & \\
LARGE & $69.49^{\mathrm{c}}$ & $49.19^{\mathrm{a}}$ & \\
\pm SEM & 0.78 & 1.54 & \\
P-value & 0.03 & 0.001 & \\
\hline
\end{tabular}

a.b.c : Means with different superscripts within a column are significantly different $(\mathrm{P}<0.05)$

Table.4: Effects of egg sizes on yolk, albumen and chick weight

\begin{tabular}{llllll}
\hline Parameters & Small & Medium & Large & \pm SEM & P-value \\
\hline Average Egg Weight $(\mathrm{g})$ & $54.99^{\mathrm{c}}$ & $65.82^{\mathrm{b}}$ & $72.19^{\mathrm{a}}$ & 1.00 & 0.001 \\
Average Chick Weight $(\mathrm{g})$ & $38.79^{\mathrm{c}}$ & $42.72^{\mathrm{b}}$ & $49.19^{\mathrm{a}}$ & 1.54 & 0.001 \\
\hline
\end{tabular}




\begin{tabular}{llllll} 
Parameters & Small & Medium & Large & \pm SEM & P-value \\
\hline Yolk Weight $(\mathrm{g})$ & $18.11^{\mathrm{b}}$ & $22.17^{\mathrm{a}}$ & $22.34^{\mathrm{a}}$ & 0.31 & 0.01 \\
Albumen Weight (g) & $27.94^{\mathrm{c}}$ & $33.69^{\mathrm{b}}$ & $40.00^{\mathrm{a}}$ & 0.70 & 0.03 \\
\% Yolk Weight & $32.86^{\mathrm{a}}$ & $33.71^{\mathrm{a}}$ & $30.99^{\mathrm{b}}$ & 0.25 & 0.01 \\
\% Albumen Weight & $50.85^{\mathrm{b}}$ & $51.08^{\mathrm{b}}$ & $55.38^{\mathrm{a}}$ & 0.38 & 0.03 \\
\% Egg/Chick Weight & $70.21^{\mathrm{a}}$ & $64.01^{\mathrm{c}}$ & $68.72^{\mathrm{b}}$ & 0.71 & 0.014 \\
Egg/Chick Weight Loss (g) & $16.50^{\mathrm{a}}$ & $22.49^{\mathrm{b}}$ & $22.61^{\mathrm{b}}$ & 0.71 & 0.02 \\
\% Egg/Chick Weight Reduction & $29.79^{\mathrm{a}}$ & $35.99^{\mathrm{b}}$ & $31.28^{\mathrm{a}}$ & 0.71 & 0.02 \\
\hline
\end{tabular}

a.b.c : Means with different superscripts within a row are significantly $(\mathrm{P}<0.05)$ different

Table.5: Regression equations derived from parameters of the relationship between the day-old chick weight and other egg qualities

\begin{tabular}{llll}
\hline Parameters & Regression equation & $\mathbf{R}^{2}$ & P value \\
\hline Day-old Chick Weight vs Egg size & $\mathrm{Y}=12.48+0.49 \mathrm{X}_{1}$ & 0.57 & 0.001 \\
Day-old Chick Weight vs Yolk Weight & $\mathrm{Y}=20.62+1.12 \mathrm{X}_{2}$ & 0.29 & 0.001 \\
Day-old Chick Weight vs Albumen Weight & $\mathrm{Y}=17.95+0.77 \mathrm{X}_{3}$ & 0.68 & 0.001 \\
\hline
\end{tabular}

Where $\mathrm{Y}=$ Day-old Chick Weight, $\mathrm{X}_{1}=$ Egg size, $\mathrm{X}_{2}=$ Yolk Weight and $\mathrm{X}_{3}=$ Albumen Weight 